\title{
A review of normative data for parameters of functional non-strabismic binocular vision
}

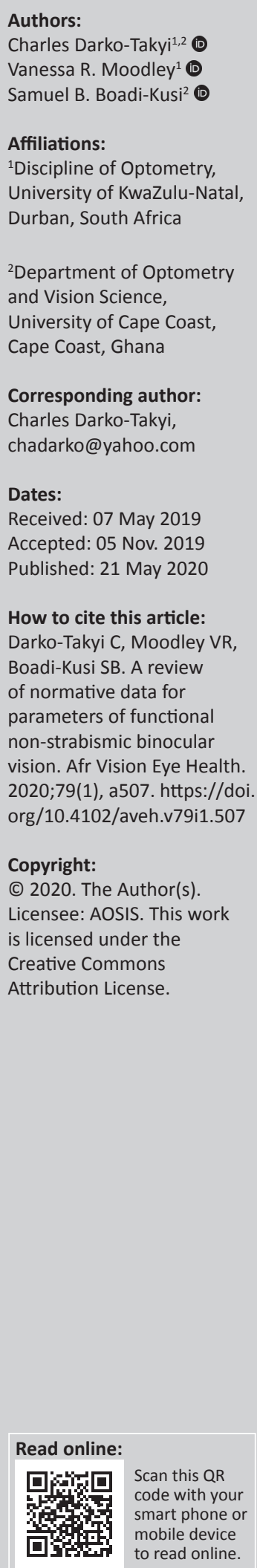

Background: There was a need to document population-expected normative data for parameters of non-strabismic binocular vision (NSBV) as the analysis and diagnosis of binocular vision disorders required comparison of patient's clinical signs with expected data in their specific population.

Aim: This article sought to review and map population-expected continental normative data for visual function parameters for evaluating the functional non-strabismic accommodative and vergence system, as these systems are very relevant to evaluate the comfort of visual system.

Method: Search engines - namely, Google Scholar, Microsoft Academic, Web of Science database and Ovid MEDLINE database - were used to search studies published in English across different continents using keywords such as 'normative or expected data' and 'specific NSBV parameter'. Results were summarised in tables for easy comparison; data were presented based on the geographical location, year of publication, demographics of the population studied and the techniques used for measuring the parameters. A summary of observed challenges with reviewed works and recommendations for the future studies are indicated. The article is delimited to studies published between 1910 and September 2019 only.

Results: Most of the studies investigated specific parameters of either accommodation only or vergence only; few recent studies have comprehensively investigated both parameters. Most studies were conducted in North America followed by Asia and Europe, with a few in Africa. No studies were found with Oceania populations. There were discrepancies and differences in methodologies and techniques used by the studies reviewed and normative data varied among different continents and different populations within each continent.

Conclusion: As the observed differences in reviewed studies could be attributed to differences in test techniques, the future studies should consider using identical, reliable, repeatable, objective and subjective techniques with good methodological designs to clarify these results. More studies should be conducted in African and Oceania populations.

Keywords: non-strabismic binocular vision (NSBV); visual function parameters; accommodative parameters; vergence parameters.

\section{Introduction}

According to $\mathrm{O}^{\prime}$ Connor, ${ }^{1}$ normative data comprise observations that characterise what is usual or expected in a defined or reference population. This definition emphasises 'reference population' indicating that normative data vary among populations. In relation to binocular vision (BV), normative data here refer to population-expected visual function parameters for vergence and accommodation. These parameters of accommodation and vergence are important measures to consider in assessing and classifying non-strabismic BV status and anomalies. ${ }^{2,3}$ Recent studies ${ }^{4,5,6,7,8,9}$ have acknowledged that visual function parameters differ among different populations and indicate the need for population-specific normative data. Population, in this sense, is defined in terms of race, ethnicity, gender and age as these are the variables thought to influence accommodation and vergence. ${ }^{4,10,11}$ These differences in parameters can be attributed to the anatomic differences in the eye, ${ }^{12,13}$ which can lead to differences in refractive status ${ }^{14,15}$ and in parameters of accommodation and vergence. $^{2,3}$ Accurate BV examination, diagnosis and management require reference to the 
normative data in the specific patient's population. ${ }^{6,7.8,9}$ Even though the aetiology of $\mathrm{BV}$ anomalies is either functional or non-functional in origin, ${ }^{2}$ this article reviews existing literature on normative data for vision parameters of functional, non-strabismic accommodative and vergence systems.

\section{Methods}

A review of literature was conducted using search engines, namely, Google Scholar, Microsoft Academic, Web of Science database and Ovid MEDLINE database. Keywords such as 'normative or expected non-strabismic BV functions', 'normative or expected vergence functions', 'normative or expected accommodative functions', 'normal stereopsis' and 'normative or expected with specific visual function parameter' (e.g. normative or expected near point of convergence [NPC]) revealed numerous papers. For original studies, all articles in their references were also included in the search. This article presents studies written in English only and is aimed at establishing evidencebased normative data for BV parameters. Emphasis was placed on the following: general studies in terms of race, specific studies of children, adults, and clinic and nonclinic patients. Studies are presented according to geographical region and year of publication arranged chronologically. Emphasis is also placed on the specific test techniques used in studies. The use of the term 'distance' means the technique was performed at $6 \mathrm{~m}$, and the use of the term 'near' means the technique was performed at $0.4 \mathrm{~m}$. A summary of observed challenges with reviewed papers and recommendations for future studies are also presented. This article is limited to studies published between 1910 and September 2019.

\section{Ethical considerations}

Ethical clearance was obtained from the Biomedical Research Ethics Committee (BREC) at the University of KwaZuluNatal (number: BE275/17).

\section{Results}

\section{Normative data studies in North and South America}

Early studies on normative data for BV parameters (Table 1) commenced in the 1940s and were conducted mainly in the United States. Some early studies ${ }^{16}$ had investigated problems in schoolchildren and found most of these to be near vision function anomalies. Other studies investigated the most probable or expected data to compare findings. Commonly, Donder's and Duane's tables and Hofstetter's equations served as standard expected measures for evaluating amplitude of accommodation (AA) ${ }^{17}$ Haines $^{18}$ and Morgan ${ }^{19}$ determined normal values for visual function parameters of accommodation and vergence in pre-presbyopic patients. Shepard ${ }^{20}$ determined expected vergence function data in 56 adults and children. Morgan ${ }^{19}$ indicated that his expected values applied to populations and not to individuals and emphasised that they do not necessarily indicate that a patient has an anomaly of BV if only one parameter falls outside the normal range. ${ }^{21}$ Wesson ${ }^{22}$ focused on studying fusional vergences with the use of prism bars in 79 clinic participants aged $4-70$ years.

The Optometric Extension Programme (OEP) expected values were not derived from population statistics but resulted from thousands of clinic participants of varying age groups. ${ }^{23}$ These values went through a standardisation process from the clinical experiences of practitioners; ${ }^{23}$ the specific process of standardisation, however, was not defined

TABLE 1: Expected values for vergence and accommodative functions from the early American studies between 1910 and 1999.

\begin{tabular}{|c|c|c|c|c|c|c|c|}
\hline BV Test & Haines $^{18}$ & Shepard ${ }^{20}$ & Morgan $^{19,21}$ & OEP $P^{23}$ & Wesson 22 & Scheiman et al. ${ }^{29}$ & Sheedy and Saladin ${ }^{34}$ \\
\hline Study population & Non-presbyopes & Adults and children & Pre-presbyopes & Clinic patients & 4-70-years-old & Schoolchildren & Optometry students \\
\hline D LH (pd) & $0 \pm 1 \mathrm{VG}$ & 1 exo \pm 2.5 & 1 exo \pm 2 & 0.5 exo & - & - & I exo \pm 4 \\
\hline$N$ LH $(p d)$ & 4.8 exo \pm 3.2 VG & 5 exo \pm 5 & 3 exo \pm 3 & 6.0 exo & - & - & - \\
\hline $\mathrm{D} V \mathrm{H}(\mathrm{pd})$ & $<1 \mathrm{pd} \mathrm{VG}$ & - & - & - & - & - & - \\
\hline D BI (break) & - & - & $7 \pm 3$ & 9 & - & - & $8 \pm 3$ \\
\hline D BI (recovery) & - & - & $4 \pm 2$ & 5 & - & - & $5 \pm 3$ \\
\hline D BO (blur) & - & - & $9 \pm 4$ & 7 & - & - & $15 \pm 7$ \\
\hline D BO (break) & - & - & $19 \pm 8$ & 19 & - & - & $28 \pm 10$ \\
\hline D BO (recovery) & - & - & $10 \pm 4$ & 10 & - & - & $20 \pm 11$ \\
\hline N BI (blur) & - & - & $13 \pm 4$ & 14 & - & - & - \\
\hline N BI (break) & $19-25$ & $20 \pm 5.5 \mathrm{~A}$ & $21 \pm 4$ & 22 & $13 \pm 5 \mathrm{~PB}$ & $12 \pm 5$ PB & - \\
\hline N BI (recovery) & $8-18$ & $11 \pm 4 \mathrm{~A}$ & $13 \pm 5$ & 18 & $10 \pm 4 \mathrm{~PB}$ & $7 \pm 4$ PB & - \\
\hline N BO (blur) & - & - & $17 \pm 5$ & 15 & & - & - \\
\hline N BO (break) & $17-28$ & $25 \pm 11 \mathrm{~A}$ & $21 \pm 6$ & 21 & $19 \pm 11 \mathrm{~PB}$ & $23 \pm 8 \mathrm{~PB}$ & - \\
\hline N BO (recovery) & $12-22$ & $13 \pm 7.5 \mathrm{~A}$ & $11 \pm 7$ & 15 & $14 \pm 9$ PB & $16 \pm 6 \mathrm{~PB}$ & - \\
\hline AA (D) & DOT & Minimum $9 \mathrm{D}$ (8 years) & $18-(1 / 3)$ age \pm 2.00 PU DUT & - & - & - & - \\
\hline$A R(D)$ & $1.0 \pm 0.4$ & - & $0.50 \pm 0.50 \mathrm{FCC}$ & 0.50 FCC & - & - & - \\
\hline NRA & $+2.06 \pm 0.2$ & - & $+2.00 \pm 0.50$ & +2.00 & - & - & - \\
\hline PRA & $-2.00 \pm 0.4$ & - & $-2.37 \pm 1.00$ & -2.25 & - & - & - \\
\hline
\end{tabular}

$\mathrm{D}$, distance which means the test was done at $6 \mathrm{~m} ; \mathrm{N}$, near which means the test was done at $0.4 \mathrm{~m}$; LH, lateral heterophoria; VG, Von-Graefe technique; pd, Prism Dioptre; VH, vertical heterophoria, $\mathrm{BI}$, base in; BO, base out; PB, prism bar; exo, exophoria; AA, amplitude of accommodation; AR, accommodation response; AF, accommodative facility; PU, push up technique; NRA, negative relative accommodation; PRA, positive relative accommodation; DOT, Donder's Table; DUT, Duane's table; FCC, fused cross-cylinder method; A, general working adults; hyphen, means not applicable as the specific study did not report values for such parameters. 
clearly. The OEP data were minimum estimated values required for persons to withstand the impact of near point stress whilst maintaining satisfactory performance; thus, standard deviations were not indicated..$^{23}$

These classic studies ${ }^{18,19,20}$ on expected values did not investigate data for all the parameters of vergence and accommodation. None of the studies involved normative data for NPC break and recovery, vertical heterophorias, accommodative facility or stereopsis (Table 1). Freier and Pickwell ${ }^{24}$ in their study on physiological exophoria sampled 663 participants aged 5-74 years and, using the Maddox rod technique, recorded values for distance heterophoria (0.84-1.50 $\Delta$ esophoria) and near heterophoria (0.34-3.83 $\Delta$ exophoria). They reported that, for distance vision, the mean heterophoria in optometric clinic patients remains unchanged throughout life. ${ }^{24}$ Another study, however, followed up 100 healthy young individuals for 20 years and found an increase in distance esophoria. ${ }^{25}$

Rouse and Hutter $^{26}$ investigated normative data for accommodative response in elementary schoolchildren and recorded an expected value of $0.3 \mathrm{D} \pm 0.3 \mathrm{D}$. Zeller ${ }^{27}$ investigated normative data for accommodative facility in 18-30-year-old participants and reported 7.7 cycles per minute $(\mathrm{cpm}) \pm 5.2 \mathrm{cpm}$ expected. Scheiman et al., however, studied normative data for accommodative facility in elementary schoolchildren and found $5.0 \mathrm{cpm} \pm 2.5 \mathrm{cpm}$ expected. ${ }^{28}$ Scheiman et al. also investigated normative data for step vergence in elementary schoolchildren in the United States and provided expected measures for negative fusional vergence and positive fusional vergence breaks and recovery (Table 1$).{ }^{29}$

Hayes et al. investigated the normative values of NPC in third and sixth grade elementary schoolchildren using the push-up (PU) technique and found a break of $4.3 \mathrm{~cm} \pm 3.4 \mathrm{~cm}$ and a recovery of $7.2 \mathrm{~cm} \pm 3.9 \mathrm{~cm} \cdot{ }^{30}$ A study by Walline et al. investigated heterophoria in 1495 schoolchildren using the cover test and found heterophoria measures for different levels. ${ }^{31}$ Walline et al. ${ }^{31}$ determined distance heterophoria in kindergarten children $(0.01 \Delta$ exophoria $\pm 0.39 \Delta$ exophoria), second-grade children (0.04 $\Delta$ exophoria $\pm 0.67 \Delta$ exophoria) and fifth-grade children $(0.02 \Delta$ exophoria $\pm 0.51 \Delta$ exophoria). The authors ${ }^{31}$ determined near heterophoria in kindergarten children $(0.62 \Delta$ exophoria $\pm 1.46 \Delta$ exophoria), second-grade children $(0.49 \Delta$ exophoria $\pm 0.60 \Delta$ exophoria) and fifth-grade children $(0.26 \Delta$ exophoria $\pm 1.59 \Delta$ exophoria). Jackson and Goss ${ }^{32}$ using the Von Graeffe technique on 244 participants aged 9-15 years recorded distance heterophoria of $1 \Delta$ exophoria $\pm 2 \Delta$ exophoria and near heterophoria of $3 \Delta$ exophoria $\pm 4 \Delta$ exophoria. Letourneau and Giroux, ${ }^{33}$ in a sample of 2035 North American participants aged 6-13 years, found a distance heterophoria of $0.57 \Delta$ esophoria $\pm 2.54 \Delta$ exophoria, and a near heterophoria of $0.78 \Delta$ exophoria $\pm 4.51 \Delta$ exophoria in 2029 participants using the Maddox rod technique. Sheedy and Saladin ${ }^{34}$ reported normative data for heterophorias and distance fusional vergence amplitudes at far among healthy optometry studens with no asthenopic sympotns (Table 1). However, the authors did not indicate whether values were applicable to all age groups or to specific ages only.

The challenge with studies conducted in the United States is that the racial profile of a specific population studied, whether white, black or Latino Americans, was not specified. Most of the early studies conducted in the United States did not specify the age range of participants but only described the study population as presbyopic, pre-presbyopic, schoolchildren, adults and clinic patients (Table 1).

More recent studies (Table 2) conducted in the United States, such as Scheiman et al., ${ }^{35}$ have determined normative data for NPC using different targets, namely, accommodative target, penlight and penlight with red-green glasses. Normal participants with monocular 20/20 visual acuity for distance and near with the best refractive correction had no strabismus or non-strabismic binocular vision (NSBV) anomalies using traditional normative values as standards. ${ }^{19,27}$ Lyon et al..$^{36}$ investigated normative data for fusional vergence break and recovery parameters at near for base-out and base-in prisms as well as the modified Thorington test phoria in 6-11-yearold normal children (Table 2). Maples et al. ${ }^{37}$ investigated for NPC norms in elementary schoolchildren aged 8-13 years using the push-up technique and found a break of $4.2 \mathrm{~cm}$ $\pm 3.4 \mathrm{~cm}$ and a recovery of $9.8 \mathrm{~cm} \pm 4 \mathrm{~cm}$ (Table 2). The expected values for accommodative and vergence testing reported by Scheiman and Wick ${ }^{3}$ were obtained from the results of different studies, including Morgan's ${ }^{19}$ table of expected findings. These values by Scheiman and Wick $^{3}$ comprehensively reported normative data (Tables 2 and 3) for all parameters of accommodation and vergence required for diagnosis and management of functional NSBV anomalies and served as modern standards.

Taub and Shallow-Hoffman ${ }^{38}$ compared three clinical tests of accommodation with Hofstetter's norms in 6-13-year-old children using the push-up technique to determine a mean AA of 15.4 D (Table 3). Based on the fact that Hofstetter's equations for $\mathrm{AA}$ were derived from studies that have various limitations, Castagno et al. ${ }^{39}$ conducted a study in 6-16-year-old urban children in Brazil to investigate expected data for the amplitude of accommodation. Their study ${ }^{39}$ reported median AA data for specific ages (Table 3) and proposed the use of median and percentiles to define AA standards to avoid outlier effects. In Castagno et al.'s study, ${ }^{39}$ in which $2.8 \%$ of participants' AA was $2 \mathrm{D}$ lower than Hofstetter's minimum, normal participants were children with visual acuity better than $20 / 25$ in either eye after fogging test, stereoscopic vision better than $100 \mathrm{sec}$ arc, and not having strabismus.

With limited data from different countries, in America, the expected data for accommodative and vergence parameters compiled by Scheiman and Wick ${ }^{3}$ serve as current standards for American populations as it indicates data for different age 

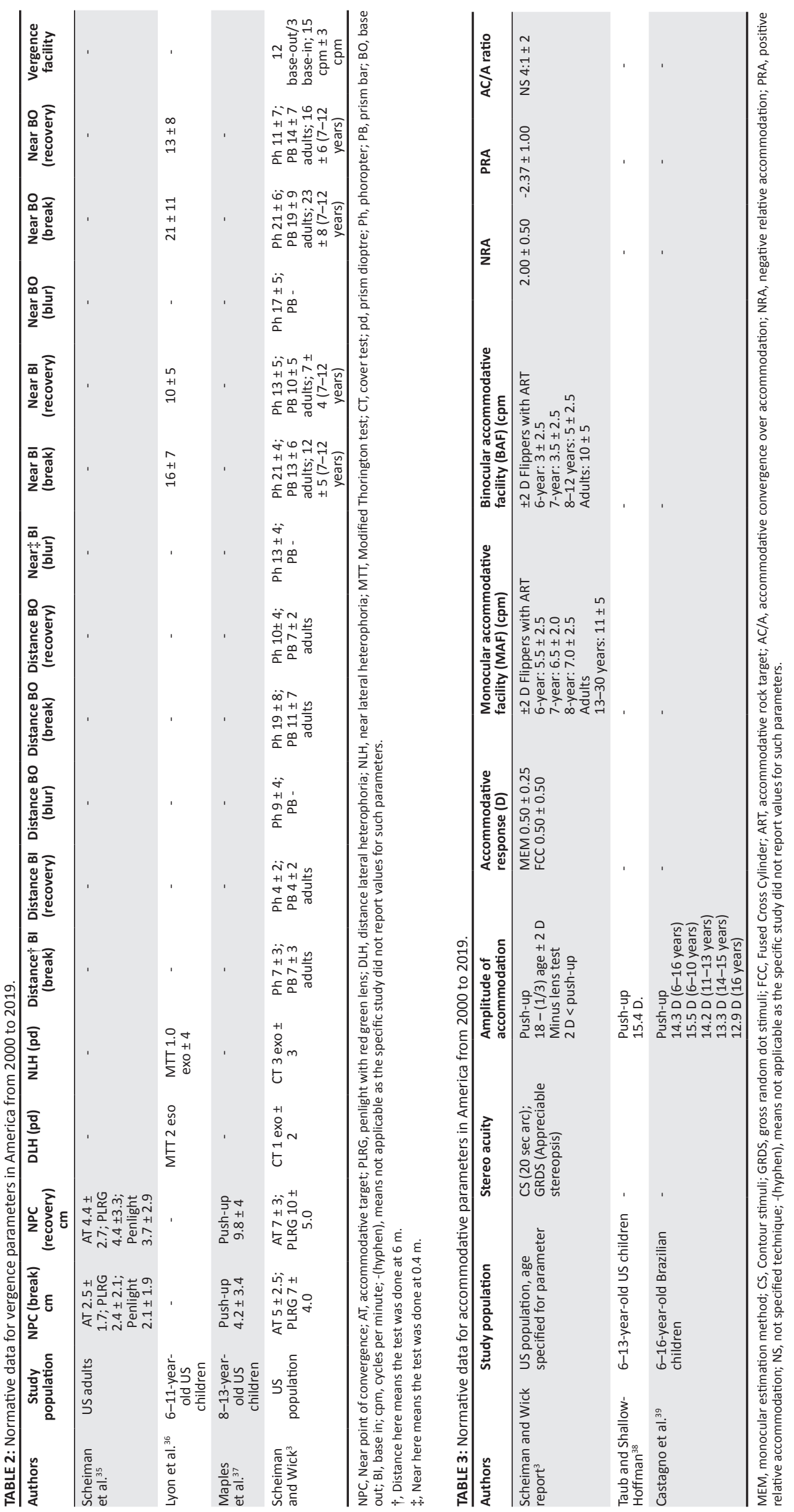
groups within the continent. Castagno et al.'s ${ }^{39}$ values for AA serve as current standards for Brazilian children.

\section{Normative data studies in Europe}

The oldest study reviewed ${ }^{40}$ among Europeans was published in 1990. Dowley ${ }^{40}$ sampled 925 participants aged 18-42 years and recorded a distance heterophoria of orthophoria using modified Maddox techniques. The participants had stable refractive errors, were asymptomatic and had stereopsis of $60 \mathrm{sec}$ arc using the TNO stereo test. All other studies reviewed were conducted in the 21st century and few have investigated both vergence and accommodation parameters.

Jimenez et al. ${ }^{5}$ conducted a study in a non-clinical paediatric population in Spain to evaluate the evolution of accommodative functions and development of ocular movements. In this study, ${ }^{5}$ they provided mean expected values for each age group for the parameters of accommodation, namely, accommodative amplitude, accommodative facility and accommodative response. The mean values with standard deviations of accommodative parameters measured for participants (aged 6-12 years) are provided in Table 4 . Another report by Jimenez et al. ${ }^{10}$ in elementary schools in the city of Granada, Spain, investigated binocular function in a paediatric population. Participants in that study $^{10}$ had no ocular diseases, suppression or systemic diseases. According to the authors, ${ }^{10}$ differences in age groups, although statistically significant, were not clinically relevant.

Sterner et al. ${ }^{41}$ investigated AA in schoolchildren in Sweden. Normal participants for the study comprised children with no astigmatism, amblyopia, strabismus or anisometropia. According to the study, ${ }^{41}$ the AA measures (Table 4) were not as good as expected when compared with Hofstetter's minimum values. McClelland ${ }^{42}$ reported normative data for accommodative lag using dynamic retinoscopy (Nott retinoscopy) in healthy school-age children in Northern Ireland. In that study, ${ }^{42}$ only schoolchildren with visual acuity of $6 / 6$ or better and children with no uncorrected refractive errors were selected as normal participants. McClelland ${ }^{42}$ recorded age-expected normative data across age groups for each of three stimuli test distances with accommodative demands of $4 \mathrm{D}, 6 \mathrm{D}$ and $10 \mathrm{D}$ as indicated in Table 4 . There was no statistically significant difference in mean accommodative responses across the age groups for the three stimuli test distances. ${ }^{42}$

Álvarez et al..$^{43}$ studied whether reference values for distance heterophoria and fusional vergence ranges for classic studies were applied to all age groups. Álvarez et al. ${ }^{43}$ determined ranges for these parameters in age categories in a visually normal large non-clinic general Spanish population. However, Alvarez et al.'s data only for the age group of 21-30 years and 31-40 years are provided here (Table 4 ) and there seem to be some differences among these age groups. ${ }^{43}$ Glerow et al. ${ }^{44}$ in their study of Swedish schoolchildren with normal stereopsis have reported expected measures for the
AA, accommodative facility and vergence facility (Table 4). Glerow et al. ${ }^{44}$ found values for binocular AA to be similar to Hofstetter's average, whilst monocular AA values were significantly lower. Lanca and Rowe, ${ }^{45}$ in a cross-sectional study, reported certain BV measures in asymptomatic Portuguese children (Table 4). These children had bestcorrected visual acuity of $0.0 \log$ MAR in either eye, compensated heterophoria of 10 prism dioptres, full ocular rotations, presence of fusional vergence and stereopsis of $60 \mathrm{sec}$ arc or better.

There is an observed larger difference in expected stereo acuity measures between the children in Spain $^{5}$ and that in Portugal. ${ }^{45}$ Stereo acuity of $60 \mathrm{sec}$ arc or better could serve as a current guide for children in Europe. With limited information on NPC in Europe, the current standards for push-up NPC break for European children aged less than 14 years are within an estimated average of $6.4 \mathrm{~cm}$ as obtained from two European studies. ${ }^{10,45}$ The expected distance and near-lateral heterophoria (NLH) for European children may range from $5 \Delta$ esophoria to $1 \Delta$ exophoria, and orthophoria to $4 \Delta$ exophoria, respectively. ${ }^{10,43,45}$ These three studies, however, used different techniques, making value applicability difficult. The expected average push-up monocular AA for European children aged 6-13 years is estimated to be at $10 \mathrm{D}$ - $16 \mathrm{D}^{5,41,44}$ The accommodative response (lag) for European children aged 4-15 years may be estimated at $0.00 \mathrm{D}-0.80 \mathrm{D}^{5,42}$ The monocular accommodative facility (MAF) and binocular accommodative facility (BAF) measures for European children are estimated at not more than $11 \mathrm{cpm}^{5,44}$ and $9 \mathrm{cpm}$, respectively. The authors did not find any study in Europe that has investigated normative data for positive relative accommodation (PRA) and negative relative accommodation (NRA). Jimenez et al. ${ }^{5,10}$ did not evaluate for NRA and PRA, indicating that these parameters evaluate interactions between accommodative and vergence systems.

\section{Normative binocular vision data studies in Asia}

The first study in Asia by $\mathrm{Kim}^{46}$ in 1979 determined normal values for AA among South Koreans and divided participants into 13 groups based on age. This study used the minus-lensto-blur technique using Duane's single fine thread as the target. Values for age groups less than 30 years are indicated in Table 6. All other studies reviewed were published in the 21st century and four out of six studies reported measures for both parameters of accommodation and vergence; however, these four studies did not report on all parameters of accommodation and vergence.

Chen et al. ${ }^{47}$ in their study on near visual functions in children sampled 268 participants aged $2-15$ years using the Modified Maddox technique that found distance phoria of $1.29 \Delta$ exophoria. Chen and Abidin ${ }^{4}$ conducted a study comprising normal primary schoolchildren in Malaysia with a visual acuity of $6 / 6$ and better with no history of previous eye problems. Parameters measured included accommodative facility, accommodation accuracy, relative accommodation, 


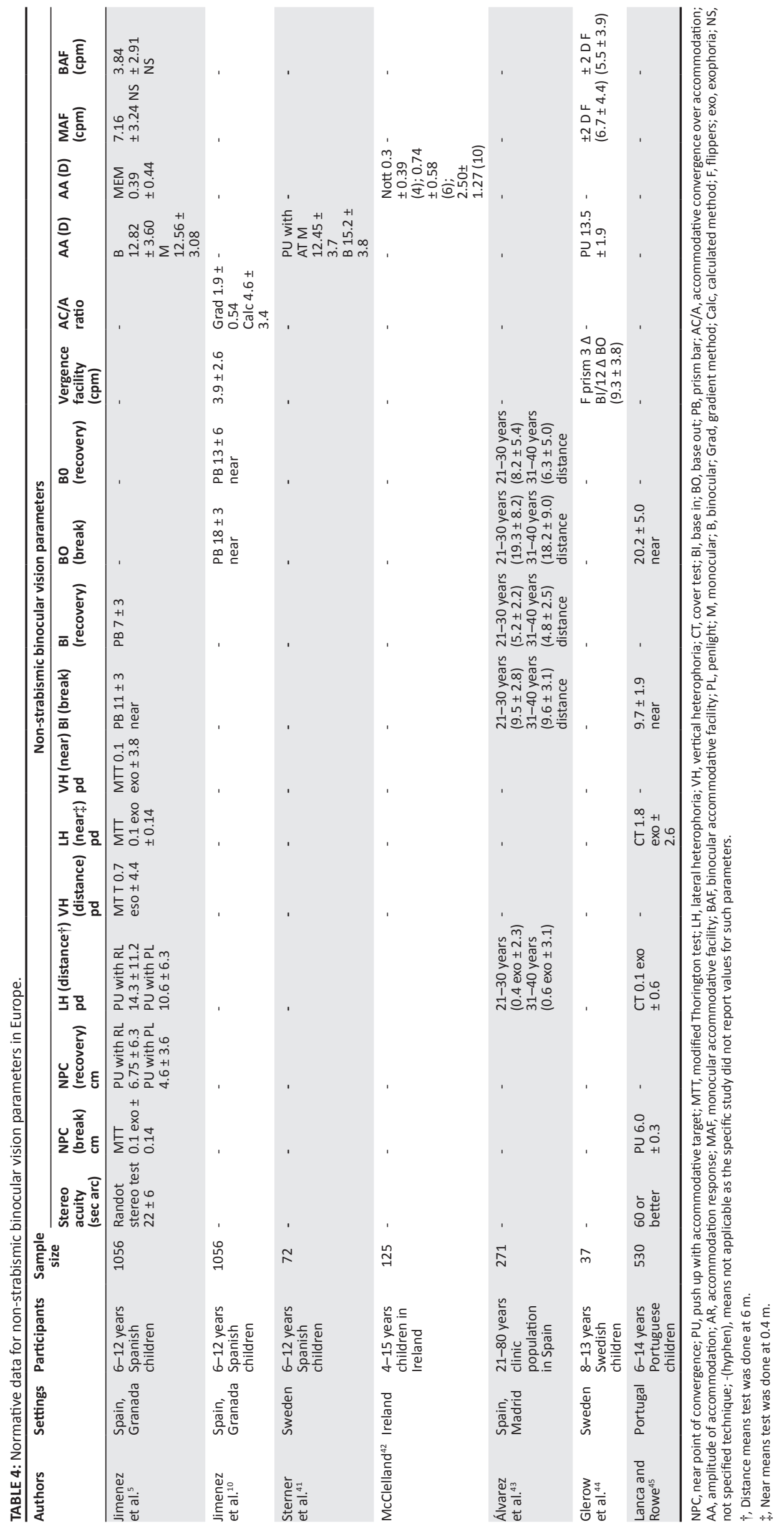


vergence facility, fusional vergence reserves and heterophoria. The mean values and standard deviations of these parameters are shown in Tables 5 and 6 . Chen and Abidin ${ }^{4}$ found significant differences among different age groups for measures of positive and negative fusional reserve at distance and negative fusional reserve at near. The specific average values of these measures are, however, not reported.

Razavi et al. ${ }^{48}$ investigated normative data for fusional vergence parameters in Iranian adults who were the target group for keratorefractive surgery (Table 5). For Razavi et al. ${ }^{48}$, the selection criteria for normal participants were adults with no significant eye disorders, including high refractive errors with best-corrected visual acuity better than $20 / 25$, stereopsis of more than $60 \mathrm{sec}$ arc and no heterotropia. There was no significant correlation between the age of participants for fusional amplitudes. ${ }^{48}$ Abraham et al. ${ }^{6}$ have investigated for normative data for NPC, accommodation and phoria in an Indian population. They used techniques that have good repeatability and reliability such as a penlight with red and green anaglyph for NPC, minus lens technique for AA and the modified Thorington method for horizontal and vertical phoria at distance and near. Patients with asthenopic symptoms were excluded using a selfadministered symptom questionnaire (a shortened version of the Convergence Insufficiency and Reading Study group questionnaire). The participants were categorised into three groups: group 1: aged 10-18 years, group 2: aged 19-27 years and group 3: aged 28-35 years. Data were recorded on the basis of these three groups (Tables 5 and 6).

Hussaindeen et al.$^{49}$ designed the 'Binocular Vision Anomalies and Normative Data' (BAND) study conducted in rural and urban schoolchildren in Tamil Nadu, India. All children underwent an initial screening protocol that involved a series of testing (e.g. visual acuity, external exams, internal exams, refraction and stereopsis assessment). After screening, children with no abnormalities had a comprehensive BV and accommodative assessment. Asymptomatic children who passed the comprehensive BV assessment protocol with no difficulty in any of the procedures were included in the normative data study. Using the above protocol, Hussaindeen et al. ${ }^{7}$ conducted a population-based cross-sectional study in a sample of Indian children and established normative data for some parameters of BV and accommodation. The mean values and standard deviations of the measured parameters (Tables 5 and 6) are compared with the measures of other studies in Asia.

Hashemi et al. ${ }^{50}$ determined normal values of accommodative amplitudes among adolescent high school students in Iran (Table 6) and found that the AA is lower in Iranian teenagers than that calculated with Hofstetter's formula. Yekta et al. ${ }^{9}$ conducted a cross-sectional study in normal young adult Iranian university students to determine binocular and accommodative characteristics and their association with age and gender. Participants with visual acuity of less than 20/25 in each eye, strabismus, pseudo myopia, latent hyperopia, ocular or systemic diseases, using topical or systemic medications and with stereopsis less than $400 \mathrm{sec}$ arc were excluded. The binocular and accommodative characteristics and their mean values in the studied sample are shown in Tables 5 and 6 . Yekta et al. ${ }^{9}$ also presented mean values and standard deviations for each of the parameters measured according to age group. The measures of positive fusional vergence break and recovery at near were higher in women, but exophoria was significantly higher in men. Some parameters, namely, NPC, distance exophoria, distance base-in-recovery and distance base-in-break, increased with age, whilst other parameters, namely, near base-out-break, AA, BAF, MAF and PRA, significantly decreased with age. The study result indicated that age and gender affect certain parameters of vergence and accommodation.

A summary of expected BV parameters from the existing studies in Asia is included below. The norms of stereo acuity for the Asian population with an age range of 18-40 years are estimated to be $45 \mathrm{sec}$ arc $-19.5 \mathrm{sec}$ arc. ${ }^{7,48}$ The push-up NPC break norms for Asian population with an age range of 7-35 years are estimated at $3 \mathrm{~cm}-8.87 \mathrm{~cm}, 7,9$ and the push-up recovery norms for Asian children aged 7-18 years are estimated to be $4 \mathrm{~cm}-8 \mathrm{~cm} .^{7}$ The standards for distance lateral heterophoria (DLH) for Asians aged 6-35 years are estimated to be $1 \Delta$ esophoria to $-3 \Delta$ exophoria., ${ }^{4,6,7,9}$ The standards for NLH for Asians children are estimated at $2 \Delta$ esophoria to $6 \Delta$ exophoria, ${ }^{4,6}$ and for adults, it ranges from $3 \Delta$ esophoria to $10 \Delta$ exophoria. ${ }^{6,9}$ The norms for vergence facility for Asian children are not less than $8 \mathrm{cpm} .{ }^{4,7}$ The expected accommodative response for Asian children aged 6-18 years is estimated at $0.25 \mathrm{D}-0.67 \mathrm{D} .{ }^{4,7}$ This is applicable to children in Malaysia and India. The expected values of MAF for the Asian population aged less than 35 years are estimated at $7 \mathrm{cpm}-17 \mathrm{cpm}^{7,9}$ using $2 \mathrm{D}$ flippers. The expected AC/A ratio for Asian children is estimated at $5 / 1,7,9$ the expected estimated range of PRA is $2.16-5.22^{4,9}$ and that for NRA is $1.75-4.04 .4,9$

\section{Normative data studies in Africa}

The first study in 1988 by Kaimbo et al. ${ }^{51}$ investigated AA in patients aged 10-58 years, who consulted the ophthalmic clinic at the University of Kinshasa, Zaire. They used the push-up method and found that AA values decreased with age, and were more notable between 30 and 40 years of age. The AA measures were lower compared with those obtained on white populations in other studies. Other studies ${ }^{8,52,53}$ were 21st-century studies and only one study, that is, Wajuihian, ${ }^{8}$ comprehensively investigated normative data for parameters of accommodation and vergence. The other three studies $^{52,53,54}$ investigated for AA and compared their results with Hofstetter's age-expected norms.

Ovenseri-Ogbomo et al. ${ }^{52}$ conducted a study in healthy Ghanaian schoolchildren (children with no refractive error and ocular abnormality at initial examination) aged 8-14 years and found a mean AA value of 16.86 D $\pm 3.07 \mathrm{D}$ using Donder's push-up method. The AA values showed a characteristic decline with increasing age. ${ }^{52}$ Among 688 normal (no refractive errors or with $\pm 0.25 \mathrm{D}$ of spherical 


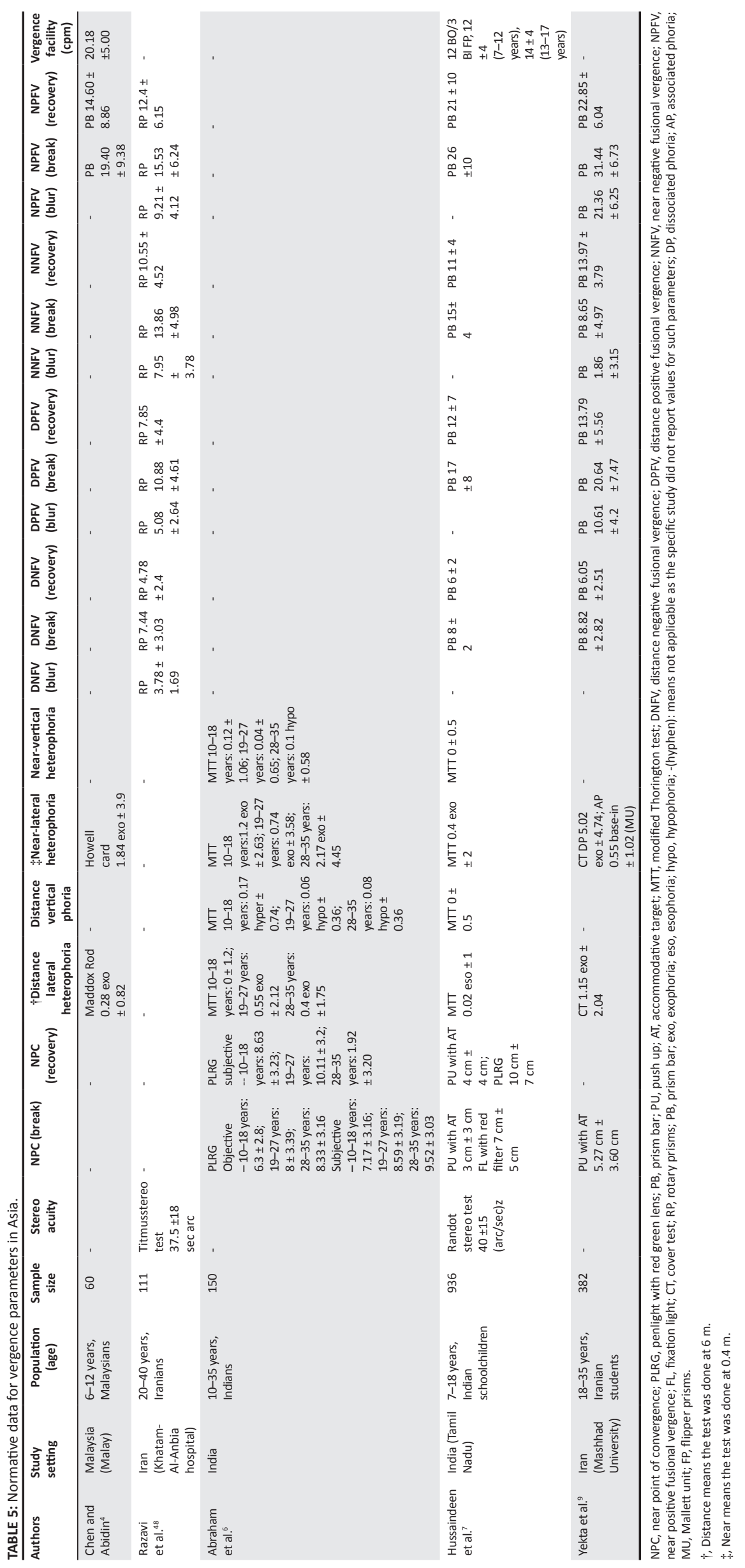


ametropia, and no ocular diseases) Nigerian schoolchildren, aged 6-16 years, Ovenseri-Ogbomo and Oduntan ${ }^{53}$ found the Donder's push-up mean AA to be $15.88 \mathrm{D} \pm 3.46 \mathrm{D}$. The results of these two similar studies ${ }^{52,53}$ were significantly higher than the minimum and average age-expected norms calculated using Hofstetter's equation.

Abu et al. ${ }^{54}$ compared different techniques for measuring AA among 352 normal (participants with best-corrected visual acuity of $0.00 \log$ MAR or better in each eye at distance and near with MEM within +0.25 to +0.75 , no strabismus, no amblyopia, no aphakia and no ocular disease) Ghanaian nonpresbyopes aged 10-39 years. They found that Hofstetter's formulae could be used to predict AA using the push-up and modified push-up methods. In their study, they indicated the mean AA value for each technique used for the following age groups: 10-19 years, 20-29 years and 30-39 years. The push-up technique recorded the highest mean amplitude of $12.50 \mathrm{D} \pm 3.30 \mathrm{D}$, modified dynamic retinoscopy was $11.60 \mathrm{D}$ $\pm 3.19 \mathrm{D}$, push-down was $10.10 \mathrm{D} \pm 2.60 \mathrm{D}$ and the minus lens method was $7.91 \mathrm{D} \pm 1.71 \mathrm{D}$.

In 1056 black South African junior high school students aged 13-18 years, Wajuihian ${ }^{8}$ determined normative data for accommodative, vergence and stereo acuity measures. His research design involved random sampling of students, and each parameter was measured thrice by only one examiner, with average values recorded as norms. Participants had no suppression, strabismus, nystagmus, ocular motility problems, ocular diseases and systemic disease and were not on any systemic medications that could affect near visual function. The specific tests performed, the techniques and instruments used and the normative data derived are summarised in Table 7.

TABLE 6: Normative data for accommodative parameters in Asia.

\begin{tabular}{|c|c|c|c|c|c|c|c|c|c|c|c|}
\hline Authors & Country & Study setting & Population & $\begin{array}{c}\text { Sample } \\
\text { size }\end{array}$ & AA (D) & $A R(D)$ & $\begin{array}{l}\text { MAF } \\
(\mathrm{cpm})\end{array}$ & $\begin{array}{l}\text { BAF } \\
(\mathrm{cpm})\end{array}$ & NRA & PRA & $\mathrm{AC} / \mathrm{A}$ \\
\hline $\mathrm{Kim}^{46}$ & Korea & - & $\begin{array}{l}6-70 \text { years } \\
\text { Koreans }\end{array}$ & 490 & $\begin{array}{l}6-10 \text { years: range } \\
16.25-11.50 ; \text { median } \\
14.50 ; \text { mean } 14.55 \\
\\
11-15 \text { years: range } \\
16.25-11.00 ; \text { median } \\
12.50 \text {; mean I2.36 } \\
\text { 16-20 years: range } \\
\text { 13.50-8.75; median } \\
10.50 \text {; mean } 10.75 \\
\\
21-25 \text { years: range } \\
12.00-5.50 ; \text { median } \\
9.00 \text {; mean } 8.86\end{array}$ & - & - & - & - & - & - \\
\hline $\begin{array}{l}\text { Chen and } \\
\text { Abidin }^{4}\end{array}$ & Malaysia & Malay & $\begin{array}{l}6-12 \text { years } \\
\text { Malaysians }\end{array}$ & 60 & - & $\begin{array}{l}\text { MEM } \\
0.4 \pm 0.27\end{array}$ & $\begin{array}{l} \pm 1.5 \mathrm{DF} \\
20.1 \pm 6.4\end{array}$ & $\begin{array}{l} \pm 1.5 \mathrm{DF} \\
19.8 \pm 6.3\end{array}$ & $\begin{array}{l}3.25 \\
\pm 0.79\end{array}$ & $\begin{array}{l}-3.90 \\
\pm 1.32\end{array}$ & - \\
\hline Razavi et al. ${ }^{48}$ & Iran & $\begin{array}{l}\text { Khatam-Al-Anbia } \\
\text { Hospital }\end{array}$ & $\begin{array}{l}20-40 \text { years } \\
\text { Iranians }\end{array}$ & 111 & - & - & - & - & - & - & - \\
\hline $\begin{array}{l}\text { Hussaindeen } \\
\text { et al. }{ }^{7}\end{array}$ & India & Tamil Nadu & $\begin{array}{l}7-18 \text { years } \\
\text { Indian } \\
\text { schoolchildren }\end{array}$ & 936 & $\begin{array}{l}\text { NS } \\
\text { B } \\
7-10 \text { years: } 13 \pm 3 \text {; } \\
11-17 \text { years: } 11 \pm 3 \\
M \\
7-10 \text { years: } 13 \pm 3 \\
11-17 \text { years: } 11 \pm 2\end{array}$ & $\begin{array}{l}\text { MEM } 0.4 \pm 0.2 \\
\text { ( } 7-12 \text { years) }\end{array}$ & $\begin{array}{l} \pm 2 \text { D F } \\
7-12 \text { years: } \\
11 \pm 4 \\
13-17 \text { years: } \\
14 \pm 5\end{array}$ & $\begin{array}{l} \pm 2 \mathrm{DF} \\
10 \pm 4 \\
\text { (7-12 years) } \\
14 \pm 5 \\
\text { (13-17years) }\end{array}$ & - & - & Grad $5.4 \pm 0.6$ \\
\hline Yekta et al. ${ }^{9}$ & Iran & $\begin{array}{l}\text { Mashhad } \\
\text { University }\end{array}$ & $\begin{array}{l}18-35 \text { years } \\
\text { university } \\
\text { students in Iran }\end{array}$ & 382 & $\begin{array}{l}\text { PU with AT } \\
11.14 \pm 2.6\end{array}$ & - & $\begin{array}{l} \pm 2 \mathrm{DF} \\
11.33 \pm 5.58\end{array}$ & $\begin{array}{l} \pm 2 \mathrm{DF} \\
8.84 \pm 4.47\end{array}$ & $\begin{array}{l}2.08 \pm \\
0.33\end{array}$ & $\begin{array}{l}-2.92 \\
\pm 0.76\end{array}$ & $\begin{array}{l}\text { NS } 4.66 \\
\pm 1.59\end{array}$ \\
\hline
\end{tabular}

AA, amplitude of accommodation; MLB, minus-lens-to blur technique; $\mathrm{M}$, monocular; $\mathrm{B}$, binocular, $\mathrm{PU}$, push-up technique; AT, accommodative target; AR, accommodation response; MAF, monocular accommodative facility; BAF, binocular accommodative facility; MEM, monocular estimation method; D, dioptres; cpm, cycles per minutes; NRA, negative relative accommodation; PRA, positive relative accommodation; F, flipper lens; AC/A, accommodative convergence to accommodation; Grad, gradient method; NS, not specified technique; -, hyphen: means not applicable as the specific study did not report values for such parameters. 
TABLE 7: Binocular vision parameters and normative data from Wajuihian. ${ }^{8}$

\begin{tabular}{|c|c|c|c|}
\hline BV test & Technique & Instrument & Normative data \\
\hline Stereopsis & Randot stereo test & Randot stereo plates & $43.9 \pm 25.2 \mathrm{sec}$ arc \\
\hline NPC (break) & PU using AT & RAF rule using VLT & $6.9 \mathrm{~cm} \pm 2.9 \mathrm{~cm}$ \\
\hline NPC (recovery) & PU using AT & RAF rule using VLT & $9.5 \mathrm{~cm} \pm 3.5 \mathrm{~cm}$ \\
\hline $\mathrm{DLH}(\mathrm{pd})$ & $\begin{array}{l}\text { Von Graefe } \\
\text { technique }\end{array}$ & phoropter & 0.09 exo \pm 1.7 \\
\hline $\mathrm{DVH}(\mathrm{pd})$ & $\begin{array}{l}\text { Von Graefe } \\
\text { technique }\end{array}$ & phoropter & $0.03 \pm 0.3$ \\
\hline $\mathrm{NLH}(\mathrm{pd})$ & $\begin{array}{l}\text { Von Graefe } \\
\text { technique }\end{array}$ & phoropter & 1.78 exo \pm 4.2 \\
\hline $\mathrm{NVH}(\mathrm{pd})$ & $\begin{array}{l}\text { Von Graefe } \\
\text { technique }\end{array}$ & phoropter & $0.03 \pm 0.4$ \\
\hline NNFV (break) & Step vergence & Horizontal PB & $17.4 \pm 5.5$ \\
\hline NNFV (recovery) & Step vergence & Horizontal PB & $12.5 \pm 4.2$ \\
\hline NPFV (break) & Step vergence & Horizontal PB & $25.4 \pm 9.2$ \\
\hline NPFV (recovery) & Step vergence & Horizontal PB & $17.5 \pm 6.8$ \\
\hline AA & Donder's PU & RAF near point rule & $15.6 \mathrm{D} \pm 3.2 \mathrm{D}$ \\
\hline pAR & MEM technique & $\begin{array}{l}\text { Streak retinoscope } \\
\text { and trail lens }\end{array}$ & $0.6 \mathrm{D} \pm 0.2 \mathrm{D}$ \\
\hline MAF & Flipper lenses & \pm 2 D flipper lens & $8.7 \mathrm{cpm} \pm 3.4 \mathrm{cpm}$ \\
\hline BAF & Flipper lenses & \pm 2 D flipper lens & $8.8 \mathrm{cpm} \pm 3.5 \mathrm{cpm}$ \\
\hline NRA & - & Phoropter & $2.17 \pm 0.48$ \\
\hline PRA & - & Phoropter & $-2.44 \pm 0.71$ \\
\hline
\end{tabular}

NPC, near point of convergence; PU, push-up technique; AT, accommodative target; RAF, Royal Air Force; VLT, vertical line target; DLH, distance lateral heterophoria; DVH, distance vertical heterophoria; NLH, near-lateral heterophoria; NVH, near-vertical heterophoria; $\mathrm{pd}$ prism dioptres; exo, exophoria; NNFV, near negative fusional vergence; PB, prism bar; NPFV, near positive fusional vergence; $A A$, amplitude of accommodation; $A R$, accommodation response; MEM, monocular estimated method; MAF, monocular accommodative facility; BAF, binocular accommodative facility; NRA, negative relative accommodation; PRA, positive relative accommodation.

As illustrated above, five normative data studies were conducted among Africans, four of which investigated only AA; hence, a critical comparison between data could only be conducted using AA values. The push-up AA test value by Abu et al. ${ }^{54}$ (mean age: $14.2 \pm 2.7$ years) was $14.25 \mathrm{D} \pm 3.33 \mathrm{D}$, that of Ovenseri-Ogbomo et al..$^{52}$ (mean age: $11.11 \pm 1.9$ years) was $16.86 \mathrm{D} \pm 3.07 \mathrm{D}$ and that of Wajuihian ${ }^{8}$ (mean age: $15.8 \pm$ 1.58 years) was $15.6 \mathrm{D} \pm 3.19 \mathrm{D}$. Even though the Abu et al.' $\mathrm{s}^{54}$ and Ovenseri et al.'s ${ }^{52}$ studies were conducted among Ghanaians at a similar location, difference in AA results could be attributed to age differences. With AA increasing with decreasing age, it was expected that the values found by Abu et al..$^{54}$ would be higher than those by Wajuihian, ${ }^{8}$ but this was not the case. In the studies conducted by OvenseriOgbomo et al. ${ }^{52}$ and Wajuihian, ${ }^{8}$ even though age ranges were different, mean AA values were the same. This indicates that AA values could be different between two different populations; it could also be possible that differences in methodologies (sample size and criteria for selection of normal participants) may have influenced inconsistencies in results. Apart from AA values, which are considered to be different in African populations, the data for BV parameters by Wajuihian ${ }^{8}$ may serve as current standards for black African populations.

\section{Discussion}

\section{Comparing normative data across continents}

Comparing the average values and range of normative data of studies conducted in similar age groups, the following findings and conclusions are made from the summary normative consensus from different continents. The average push-up NPC break is comparable between African $(6.9 \mathrm{~cm})$ and European children $(6.4 \mathrm{~cm})$; the average push-up NPC break is slightly lower for wider age range of American children and adults $(5 \mathrm{~cm})$ compared with a wider age range of Asian children and adults $(6 \mathrm{~cm})$. The range of push-up NPC recovery is, however, higher in African children $(6 \mathrm{~cm}-13 \mathrm{~cm})$ than in Asian children $(4 \mathrm{~cm}-8 \mathrm{~cm})$. The expected range for DLH in Americans is comparable with that of Asians ( $1 \Delta$ esophoria to $3 \Delta$ exophoria), slightly different from Africans ( $2 \Delta$ esophoria to $2 \Delta$ exophoria) but lower in range than Europeans (5 $\Delta$ esophoria to $1 \Delta$ exophoria). The expected range values for NLH are different for different continents, being orthophoria to $6 \Delta$ exophoria for Americans, orthophoria to $4 \Delta$ exophoria for European children and comparable between Asian and African children (2 $\Delta$ esophoria to $6 \Delta$ exophoria). It could be seen that the maximum NLH does not exceed $6 \Delta$ exophoria, being comparable for Americans, Asians and Africans. The expected range of stereo acuity for African children is wider (43.9 sec arc $\pm 25.2 \mathrm{sec}$ arc) compared with Europeans (60 sec arc or better) than Asians (45 sec arc - $19.5 \mathrm{sec}$ arc).

The expected average MAF is higher for European children (11 cpm) as compared to African children (8.7 cpm), who have a lower average than American children $(6.5 \mathrm{cpm})$. The expected average BAF measures in European and African children are comparable $(9 \mathrm{cpm})$; however, it is wider in range for Africans (standard deviation [SD] \pm 3.5 ). The norms for vergence facility for Americans are higher (15 cpm $\pm 3 \mathrm{cpm})$ as compared to Asian children $(>8 \mathrm{cpm})$; however, the data from America were derived from a wider age range comprising children and adults. The range for accommodative response (0.25-0.75) is comparable among Americans, Asians, Europeans and Africans. It is, however, slightly higher for Europeans by approximately $1 \mathrm{D}$. The range of NRA is greater in Asian populations $(1.75 \pm 4)$, compared with Americans $(2.00 \pm 0.5)$ and Africans $(2.17 \pm 0.48)$. The expected range of PRA is wider for the Asian population (-2.16 to -5.22$)$, and comparable between the American population $(-2.37 \pm 1.00)$ and African population $(-2.44 \pm 0.71)$. The expected gradient $\mathrm{AC} / \mathrm{A}$ ratio is higher for Asian children (5:1) as compared to European children $(1.9 \pm 0.54: 1)$. There is a lack of consensus on AA measures within and across continents. The Hofstetter's equations guide AA data for Americans; however, in other continents it may not be applicable.

\section{Challenges regarding reviewed studies}

The most commonly and widely used criteria for NSBV are that of Morgan ${ }^{19}$ and Scheiman and Wick, ${ }^{3}$ whose norms are considered as current standards. ${ }^{6,7}$ The challenge with these standards is that they were derived from the American population and thus are basically applicable to Americans assumed to be in the age range of $6-40$ years. ${ }^{7,8}$ The various studies mentioned above were conducted in different populations with different age groups using different techniques; hence, this makes direct comparison of values difficult. Hussaindeen et al. ${ }^{7}$ found certain parameters for 
$\mathrm{BV}$, namely, NPC, horizontal phoria, vergence facility, $\mathrm{AC} / \mathrm{A}$ ratio, $\mathrm{AA}$ and $\mathrm{AF}$, in the Indian population to be different compared with similar studies ${ }^{3,19,55}$ carried out in other populations, including ones considered as relevant to the current standards. Yekta et al. ${ }^{9}$ also determined measures that were significantly different from current standards.

Results of some studies were however comparable with previously published norms. Hussaindeen et al. ${ }^{7}$ found that fusional vergence ranges to be clinically comparable with previously published normative data. Gall et al. ${ }^{56}$ and Romano et al..$^{57}$ found data for vergence facility and stereopsis, respectively, to be comparable with existing literature. According to Wajuihian, ${ }^{8}$ there appears to be a consistent trend on reported results of heterophoria even though there are differences in study designs; he found that there was no marked difference between expected values for near phoria, fusional vergence, relative accommodation and accommodative response between his study and other reviewed ones. Copobianco ${ }^{58}$ reported that there is no difference between the NPC break points obtained using an accommodative target or penlight in normal subjects. Hussaindeen et al., ${ }^{7}$ however found in their recent study that there is a significant difference in the break and recovery values of NPC between accommodative target and penlight with a red filter.

There are discrepancies in criteria for defining 'normal' participants in reviewed studies, and this is a challenge. The questions that arise are how normal were the participants and what parameters should be considered to define 'normal' participants to determine expected parameters for the BV system? Hussaindeen et al. ${ }^{49}$ defined good criteria for identifying normal participants to investigate for expected BV parameters and applied this in their study that sought to investigate for expected data. ${ }^{7}$ These criteria involved conducting a preliminary vision screening to eliminate participants with poor visual acuity, ocular diseases, amblyopia, strabismus, nystagmus and poor stereopsis, and reporting comprehensive accommodative and vergence parameter results for selected participants who expressed no difficulty with these procedures.

Normative data studies require very large sample sizes representative of populations under study, but most studies reviewed here used very small sample sizes; thus, measures are not truly representative of the populations studied. Again, few studies ${ }^{39,41,46}$ recorded medians in addition to mean values and standard deviations. We recommend that new studies report, in addition to mean values and standard deviations, medians and quartile deviations or interquartile ranges to cater or correct for values that are outliers. Data normality was also usually ignored in most of the studies; however, it is important to consider data normality when collecting data. Some of the studies that investigated for expected data for AA found that their findings were different from Hofstetter's age-expected norms. ${ }^{38,39,41,44,50,52,53}$ Hofstetter's recommendation was published way back in the 1950s specifically on American children and may not be applicable to other populations. The challenge with reviewed studies was that most studies ${ }^{38,41,50,52,53,54}$ compared their mean AA values with Hofstetter's average values. Only one study ${ }^{39}$ compared AA results with Hofstetter's minimum values. It is possible that even though the mean values may be different from Hofstetter's average, the range may still be within Hofstetter's range of maximum and minimum values because of differences in standard deviations. Thus, the authors recommend that future studies compare their minimum and maximum AA range with Hofstetter's minimum and maximum values.

It is still not clear as to whether gender influences the parameters of vergence and accommodation as very few studies $^{9,50,59}$ have investigated gender biases because these affect normative data for visual function parameters. Some studies ${ }^{50,59}$ have reported that females have higher AA than age-matched males. According to other authors ${ }^{60}$, this gender difference is not caused by physiological differences in accommodation but rather because females have shorter arms than males. The shorter arms increase habitual accommodative demand for near work in females. As some BV parameters could be different at far and near, most studies investigated these parameters at far and near, whilst only one study $^{43}$ investigated and reported for heterophoria and fusional vergence parameters at distance only.

\section{Measures for classifying vergence accommodative dysfunctions}

The complicated nature of the accommodative and vergence system makes it inadequate to differentially diagnose such anomalies using only single parameters referred to as clinical signs. Correlated clinical signs or visual function parameters that form a syndromefor each anomaly best define the disorders of accommodation and vergence. ${ }^{3,8,19}$ The most common clinical signs include NPC, heterophoria, fusional vergence amplitudes, accommodative amplitudes, accommodative facility, accommodative lag, relative accommodation and stereo acuity. ${ }^{3}$ The visual parameters or clinical signs used to differentially diagnose anomalies of the vergence system include measures for fusional vergence amplitude at near and far, horizontal and vertical heterophorias at near and far, vergence facility and NPC. ${ }^{10}$ Amplitude of accommodation, accommodative response (lag or lead) and monocular accommodative facility are used to characterise the accommodative system. ${ }^{5}$ To evaluate interaction between the vergence system and the accommodative system, visual parameters, namely, NRA, PRA, BAF, stimulus AC/A ratio and stereo acuity, are used. ${ }^{10}$ Few studies s, $^{3,5,7,8,19}$ have extensively investigated expected measures for most of the visual function parameters of vergence and accommodation; most studies reviewed have investigated specific visual function parameters only. None of the studies reviewed have reported on vertical fusional vergence reserves and a few have reported on vertical phorias. ${ }^{3,6,7}$ We recommend new normative data studies to include measures for these parameters that are not well specified in the literature. Razavi et al. ${ }^{48}$ in their study 
reported measures for negative fusional vergence blur at distance (3.78 $\Delta$ ), which could possibly be because of the fact that the eyes of participants were not completely relaxed for distance with best refractive correction.

Some factors or guidelines should be considered in performing accurate visual function testing for certain parameters so as to achieve reliable and repeatable results. Heterophoria measures cannot be considered in isolation as they cannot predict symptoms. ${ }^{3,61}$ These measurements are only useful when compared with fusional vergence measures, which determine whether it (the demand) is compensated or decompensated using Sheard's criteria. ${ }^{3,61}$ One factor that greatly influences measures for fusional vergence, and must be controlled, is suppression. ${ }^{62}$ Most studies in the literature did not control for suppression during fusional vergence measurements. Wajuihian, ${ }^{8}$ however, screened for suppression with the Worth Four-Dot test before taking fusional vergence measurements and recommended that it was more appropriate to measure fusional vergence with a suppression control in place. If suppression is not controlled, it may result in high break values because the break is not detected until the stimulus is outside the suppression zone. ${ }^{62}$ In controlling for suppression, the test is stopped if the suppression is detected, resulting in lower values for break.

One study reported that NPC is dependent on age, with younger ones having worse NPC than adults. ${ }^{9}$ There is thus a need to document expected NPC results based on age. ${ }^{8,63}$ During NPC testing, the patient's convergence ability is determined and all three aspects of convergence - namely, fusional, proximal and accommodative convergence - are used. The main targets for NPC are the accommodative target and light source but they have their limitations and advantages. ${ }^{7}$ The accommodative target may not be ideal in cases of reduced AA. ${ }^{7}$ However, it produces more accurate NPC measurements and gives less variability. ${ }^{35,64}$ A light source target may cause accommodative vergence to fluctuate, possibly giving inconsistent readings because the target is a diffused low spatial frequency source. ${ }^{35}$ However, measuring NPC with a red lens may reduce the effect of voluntary convergence. It is recommended that an accommodative target should be used first because it provides more accurate readings.$^{64}$ In cases where the results from an accommodative target are borderline, or there are signs and symptoms indicative of convergence insufficiency (CI), the NPC could be repeated using a penlight target with the patient wearing redgreen filters. ${ }^{78}$ Studies have established that using a penlight target with red-green anaglyph is a more sensitive test for diagnosing convergence insufficiency. ${ }^{57,64}$

Most studies measured AA using the push-up technique. ${ }^{8}$ The minus-lens-to-blur technique, however, has been reported to underestimate $\mathrm{AA}$, whilst the push-up technique tends to overestimate AA. ${ }^{8}$ It is recommended that future studies must investigate for normative data using both pushup technique and minus-lens-to-blur technique. The accommodative facility measure is relevant to diagnose various accommodative anomalies. ${ }^{3}$ According to Wajuihian ${ }^{8}$ and others, it is recommended that suppression controls are used in measuring BAF even though some studies normally use the Worth Four-Dot test to screen for suppression as was performed in their study. According to Wajuihian, ${ }^{8}$ expected data for accommodative response across studies seem to be the most consistent accommodative measure and this may be because the test is an objective one. The relative accommodation tests are influenced by changes in refraction and indirectly measure the vergence system. ${ }^{3}$ Lastly, refractive errors, such as anisometropia, affect stereo acuity thresholds and thus must be corrected before checking stereo acuity. ${ }^{8,65}$ This is because anisometropia presents with aniseikonia and retinal disparities, and there is more fovea suppression in defocused eyes. ${ }^{65}$

\section{Conclusion}

Across the globe, most of the studies on this topic have been conducted in America, followed by Europe and Asia, with few studies conducted in Africa. Recent studies have investigated most visual function parameters for both accommodation and vergence. The reviewed normative data were determined for specific populations and age groups, and most of the studies have used different methodologies or testing. According to Hussaindeen et al., ${ }^{7}$ 'to optimise the sensitivity and specificity of diagnosis, ethnicity-specific cutoff values for BV parameters are mandatory'. Each of the expected values reviewed must be applied only to the population of the study. It was expected that studies that recorded different normative values ${ }^{7,66,67}$ may attribute their differences to variations in population, race or ethnicity rather than to methodologies and techniques used. Different study designs and mostly smaller samples in reviewed studies make it difficult to attribute differences in normative data in different studies than to differences in the population used or differences in methodology and techniques.

Again with limited studies and data in and across continents, it is difficult to draw a global consensus on these parameters of NSBV. We recommend large population-based comprehensive normative data studies (targeting parameters of both accommodation and vergence) using most reliable and repeatable, objective and subjective techniques with good methodology in different populations of each continent to clarify these differences or otherwise. In selecting normal participants, we recommend Hussaindeen et al.' $\mathrm{s}^{49}$ criteria with slight modifications, which include administering a reliable and validated asthenopic symptom questionnaire to select asymptomatic participants first before preliminary vision screening on asymptomatic participants. We also recommend including a suppression test such as the Worth Four-Dot test in preliminary vision screening to exclude participants with suppression and checking for suppression during fusional vergence and BAF measurements. Populations at risk, such as school-going children, should be the first point of consideration and authors must consider comparing these parameters among genders, as only one study ${ }^{9}$ has determined that gender affects these parameters. A few studies have suggested contrary results for gender. 
The authors did not find any normative data study for parameters of accommodation and vergence among any population in Oceania; again, few studies were conducted on the African continent, with only one documenting expected data for both parameters of accommodation and vergence. Thus, we recommend such studies to be conducted urgently to document data for different populations in Oceania and Africa. The main limitation with normative data studies is the difficulty in determining as to what extent these population means could be applied to a single individual in the clinical environment. ${ }^{20,29}$ In spite of this major limitation, ${ }^{20,29}$ these expected values (mean values with standard deviations, medians and quartile deviations) should be used as guidelines for BV case analysis in clinics especially as anomalies are interpreted as syndromes, ${ }^{8}$ with emphasis on the presence of asthenopia.

\section{Acknowledgements}

The authors wish to thank Dr Michael Ntodie for his immense contribution to the search of relevant literature for this article.

\section{Competing interests}

The authors declare that they have no financial or personal relationships that may have inappropriately influenced them in writing this review article.

\section{Authors' contributions}

C.D.T. was the primary author. V.R.M. supervised C.D.T.'s PhD studies, from which this review manuscript was drafted. S.B.B.-K. was the co-supervisor of C.D.T.'s PhD studies and contributed enormously in editing this manuscript.

\section{Funding information}

Funding for this study was received from the University of KwaZulu-Natal, South Africa.

\section{Data availability statement}

Data sharing is not applicable to this article.

\section{Disclaimer}

The views and opinions expressed in this article are those of the authors and do not necessarily reflect the official policy or position of any affiliated agency of the authors.

\section{References}

1. O'Connor PJ. Normative data: Their definition, interpretation, and importance for primary care physicians. Fam Med. 1990;22(4):307-311.

2. Von Noorden GK, Campos, EC. Binocular vision and ocular motility: Theory and management of strabismus [homepage on the Internet]. 6th ed. 2002 [cited 2018 June 15]. Available from: www.cybersight.org

3. Scheiman M, Wick B. Clinical management of binocular vision: Heterophoric accommodative and eye movement disorders. 3rd ed. Philadelphia, PA: JB Lippincott; 2008.
4. Chen AH, Abidin AHZ. Vergence and accommodation systems in Malay primary school children. Malays J Med Sci. 2002;9(1):9-15.

5. Jimenez R, Gonza' lez, MD, Perez MA, Garcla JA. Evolution of accommodative function and development of ocular movements in children. Ophthal Physiol Opt. 2003;23(2):97-107. https://doi.org/10.1046/j.1475-1313.2003.00093.x

6. Abraham NG, Srinivasan K, Thomas J. Normative data for near point of convergence, accommodation, and phoria. Oman J Ophthalmol. 2015;8(1):14-18. https://doi.org/10.4103/0974-620X.149856

7. Hussaindeen JR, Rakshit A, Singh NK, et al. Binocular vision anomalies and normative data (BAND) in Tamil Nadu: Report 1. Clin Exp Optom. 2017;100(3): 278-284. https://doi.org/10.1111/cxo.12475

8. Wajuihian SO. Normative values for clinical measures used to classify accommodative and vergence anomalies in a sample of high school children in South Africa. J Optom. 2018;12(3):143-160. https://doi.org/10.1016/j. optom.2018.03.005

9. Yekta A, Khabazkhoob M, Hashemi H, Ostadimoghaddam H. Binocular and accommodative characteristics in a normal population. Strabismus. 2017;25(1): 5-11. https://doi.org/10.1080/09273972.2016.1276937

10. Jimenez R, Perez MA, Garcia JA, Gonzalez MD. Statistical normal values of visual parameters that characterize binocular function in children. Ophthal Physiol Opt. 2004;24(6):528-542. https://doi.org/10.1111/j.1475-1313.2004.00234.x

11. Chen $A H$, Iqbal $R$. The effect of refractive error and race on the vergence and accommodation systems. ACBO Behav Optom J. 2000;8(1):5-8.

12. Blake CR, Lai WW, Edward DP. Racial and ethnic differences in ocular anatomy. Int Ophthalmol Clin. 2003;43(4):9-25. https://doi.org/10.1097/00004397200343040-00004

13. Wang MD, Guofu H, Mingguang H, Lingling W, Shan L. Comparison of anterior ocular segment biometry features and related factors among American Caucasians, American Chinese and mainland Chinese. Clin Exp Ophthalmol. 2012;40(6):542-549. https://doi.org/10.1111/j.1442-9071.2011.02746.x

14. Kleinstein RN, Jones LA, Hullett $S$, et al. Refractive error and ethnicity in children. Arch Ophthalmol. 2003;121:1141-1147. https://doi.org/10.1001/archopht.121.8.1141

15. Dadeya S, Kamlesh, Shibal F. The effect of anisometropia on binocular visual function. Indian J Ophthalmol. 2001;49(4):261.

16. Betts EA, Austin AS. Seeing problems of school children. Optom Wkly. 1940;31:1151-1153.

17. Hofstetter HW. A comparison of Duane's and Donder's tables of the amplitude of accommodation. Am J Optom Arch Am Acad Optom. 1944;21(9):345-363. https://doi.org/10.1097/00006324-194409000-00001

18. Haines HF. Normal values of visual functions and their application in case analysis. Part IV. The analysis findings and determination of normals. Am J Optom Arch Am Acad Optom. 1941:18(2):58-73. https://doi.org/10.1097/00006324194102000-00002

19. Morgan MW. The clinical aspects of accommodation and convergence. Am J Optom Arch Am Acad Optom.1944;21(8):301-313. https://doi. org/10.1097/00006324-194408000-00001

20. Shepard CF. The most probable 'expected'. Optom Wkly. 1941;32:538-541.

21. Morgan MW. The analysis of clinical data. Optom Wkly. 1964;55:27-34.

22. Wesson MD. Normalization of prism bar vergences. Am J Optom Physiol Opt. 1982;59(8):628-633. https://doi.org/10.1097/00006324-198208000-00002

23. Skeffington AM, Lesser SK, Barstow R. Near point optometry. Curriculum II. Optom extension progam courses. Santa Ana, CA: Optometric Extension Program Foundation, Oct 1947-Sep 1948:20(3), Oct 1948-Sep 1949:21(4), Oct 1949-Sep 1950:22(5).

24. Freier BE, Pickwell LD. Physiological exophoria. Ophthal Physiol Opt. 1983;3(3):267-272. https://doi.org/10.1111/j.1475-1313.1983.tb00613.x

25. Spierer A, Hefetz L. Normal heterophoric changes: 20 years' follow-up. Graefes Arch Clin Exp Ophthalmol. 1997;235:345-348. https://doi.org/10.1007/ BF00937281

26. Rouse MW, Hutter RF. A normative study of the accommodative lag in elementary school children. Am J Optom Physiol Opt. 1984:61(11):693-697. https://doi.org/10.1097/00006324-198411000-00008

27. Zellers JA, Alpert TL, Rouse MW. A review of the literature and normative study of accommodative facility. J Am Optom Assoc. 1984;55(1):31-37.

28. Scheiman M, Herzberg H, Fratz K, Margolies M. Normative study of accommodative facility in elementary school children. Am J Optom Physiol Opt. 1988;65(2): 127-134. https://doi.org/10.1097/00006324-198802000-00009

29. Scheiman $M$, Herzberg $H$, Frantz $K$, et al. A normative study of step vergence in elementary school children. J Am Optom Assoc. 1989;60:276-280.

30. Hayes GJ, Cohen BE, Rouse MW, DeLand PN. Normative values for the near poin of convergence of elementary school children. Optom Vis Sci. 1998;75(7): 506-512. https://doi.org/10.1097/00006324-199807000-00019

31. Walline JJ, Mutti DO, Zadnik K, Jones LA. Development of phoria in children. Optom Vis Sci. 1998;75(8):605-610. https://doi.org/10.1097/00006324-199808000-00026

32. Jackson TW, Goss DA. Variation and correlation of standard clinical phoropter tests of phorias, vergence ranges, and relative accommodation in a sample of school-age children. J Am Optom Assoc. 1991;62(7):540-547.

33. Letourneau JE, Giroux R. Nongaussian distribution curve of heterophorias among children. Optom Vis Sci. 1991;68(2):132-137. https://doi.org/10.1097/00006324199102000-00008 
34. Saladin JJ, Sheedy JE. Population study of fixation disparity, heterophoria and vergence. Am J Optom Physiol Opt. 1979;55(11):744-750.

35. Scheiman M, Gallaway M, Frantz KA, et al. Near point of convergence: Test procedure, target selection and normative data. Optom Vis Sci. 2003;80(3): 214-225. https://doi.org/10.1097/00006324-200303000-00011

36. Lyon WD, Goss D, Horner D, Downey J, Rainey B. Normative data for modified Thorington phorias and prism bar vergences from the Benton-IU study. Optometry. 2005;76:593-599. https://doi.org/10.1016/j.optm.2005.08.014

37. Maples WC, Hoenes R. Near point of convergence norms measured in elementary school children. Optom Vis Sci. 2007;84(3):224-228. https://doi.org/10.1097/ OPX.0b013e3180339f44

38. Taub M, Shallo-Hoffmann J. Comparison of three clinical tests of accommodation amplitude to Hofstetter's norms to guide diagnosis and treatment. Optom Vis Dev. 2012;43(4):180-190.

39. Castagno VD, Vilela MAP, Meucci RD, Resende DPM, Schneid FH, Getelina R Amplitude of accommodation in schoolchildren. Curr Eye Res. 2017;42(4): 604-610. https://doi.org/10.1080/02713683.2016.1220586

40. Dowley D. Heterophoria. Optom Vis Sci. 1990;67:456-460. https://doi. org/10.1097/00006324-199006000-00010

41. Sterner B, Gellerstedtand M, Sjöström A. The amplitude of accommodation in 6-10-year-old children - Not as good as expected! Ophthalmic Physiol Opt. 2004;24(3):246-251. https://doi.org/10.1111/j.1475-1313.2004.00201.x

42. McClelland JF, Saunders KJ. Accommodative lag using dynamic retinoscopy: Age norms for school-age children. Optom Vis Sci. 2004;81(12):929-933.

43. Álvarez CP, Puell MC, Sánchez-Ramos C, Villena C. Normal values of distance heterophoria and fusional vergence ranges and effects of age. Graefe's Arch Clin Exp Ophthalmol. 2005;244(7):821-824. https://doi.org/10.1007/s00417-005-0166-5

44. Glerow JP, Varg A, Theagarayan B. Amplitude of accommodation, accommodative and vergence facility in Swedish children. Invest Ophthalmol Vis Sci. 2014 and vergence
$55(13): 757$

45. Lanca C, Rowe FJ. Variability of fusion vergence measurements in heterophoria Strabismus. 2016;24(2):63-69. https://doi.org/10.3109/09273972.2016.1159234

46. Kim BC. The normal value of amplitude of accommodation in Koreans. J Korean Ophthalmol Soc. 1979;20(2):153-157.

47. Chen AH, O'Leary DJ, Howell ER. Near visual function in young children. Part I: Near point of convergence. Part II: Amplitude of accommodation. Part III: Nea heterophoria. Ophthal Physiol Opt. 2000;20(3):185-198. https://doi.org/10.1016/ S0275-5408(99)00056-3

48. Razavi ME, Poor SSH, Daneshyar A. Normative values for the fusional amplitudes and the prevalence of heterophoria in adults. Iran J Ophthalmol. 2010;22(3):41-46.

49. Hussaindeen JR, George R, Swaminathian M, Kapur S, Ramani KR, Scheiman M. Binocular vision anomalies and normative data (band) in Tamilnadu - Study design and methods. Vision Dev Rehab. 2015;1(4):260-271. https://doi. org/10.31707/VDR2015.1.4.p260

50. Hashemi $\mathrm{H}$, Nabovati $\mathrm{P}$, Yekta AA, et al. Amplitude of accommodation in an 11- to 17-year-old Iranian population. Clin Exp Optom. 2017;100(2):162-166. https://doi.org/10.1111/cxo.12431
51. Kaimbo K, Maertens K, Missotten L. Amplitude of accommodation in Zairian subjects. J Fr Ophtalmol. 1988;11(5):435-438.

52. Ovenseri-Ogbomo GO, Kudjawu EP, Kio FE, Abu EK. Investigation of amplitude of accommodation among Ghanaian school children. Clin Exp Optom. 2012 95(2):187-191. https://doi.org/10.1111/j.1444-0938.2011.00692.x

53. Ovenseri-Ogbomo GO, Oduntan OA. Comparison of measured with calculated amplitude of accommodation in Nigerian children aged six to 16 years. Clin Exp Optom. 2017;101(4):571-577. https://doi.org/10.1111/cxo.12520

54. Abu EK, Ocansey S, Yennu J, Asirifi I, Marfo R. Comparing different methods of measuring accommodative amplitude with Hofstetter's normative values in a Ghanaian population. Curr Eye Res. 2018;43(9):1145-1150. https://doi.org/10.10 80/02713683.2018.1480044

55. Duane A. The norms of convergence. In: Crisp WH, Finnoff WC, editors. Contributions to ophthalmic science. Menasha, WI: George Banta, 1926; p. 34-46.

56. Gall R, Wick B, Bedell H. Vergence facility: Establishing clinical utility. Optom Vis Sci. 1998;75(10):731-742. https://doi.org/10.1097/00006324-199810000-00018

57. Romano PE, Romano JA, Puklin JE. Stereoacuity development in children with normal binocular single vision. Am J Ophthalmol.1975;79(6):966-971. https://doi.org/10.1016/0002-9394(75)90679-0

58. Capobianco NM. The subjective measurement of the near point of convergence and its significance in the diagnosis of convergence insufficiency. Am Orthop J. 1952(1);2:40-42. https://doi.org/10.1080/0065955X.1952.11981061

59. Carnevali T, Southaphanh P. A retrospective study on presbyopia onset and progression in a Hispanic population. Optometry. 2005;76(1):37-46. https://doi.org/10.1016/S1529-1839(05)70253-0

60. Hickenbotham A, Roorda A, Steinmaus C, Glasser A. Meta-analysis of sex differences in presbyopia. Invest Ophthalmol Vis Sci. 2012;53:3215-3220. https://doi.org/10.1167/iovs.12-9791

61. Goss D. Ocular accommodation, convergence, and fixation disparity: A manual of clinical analysis. 1st ed. New York: Butterworth-Heinemann; 1995.

62. Wesson MD, Massen LC, Boyles ST. Objective testing of vergence ranges. J Am Optom Assoc. 1995;66(6):338-342.

63. Metsing IT, Ferreira JT. Accommodation and vergence status among the $3 \mathrm{rd}$ and 4th graders in a mainstream school in Gauteng. S Afr Optom. 2012;71(1):22-31. https://doi.org/10.4102/aveh.v71i1.64

64. Pang $\mathrm{Y}$, Gabriel H, Frantz KA, et al. A prospective study of different test targets for the near point of convergence. Ophthalmic Physiol Opt. 2010;30(3):298-303. https://doi.org/10.1111/j.1475-1313.2010.00731.x

65. Wu WW, Peng XJ. Anisometropia and stereopsis. Guoji Yanke Zazhilnt Eye Sci J. 2014;14:74-76.

66. Casillas E, Rosenfield M. Comparison of subjective heterophoria testing with a phoropter and trial frame. Optom Vis Sci. 2006;83(4):237-241. https://doi. org/10.1097/01.opx.0000214316.50270.24

67. Sanker N, Prabhu A, Ray A. A comparison of near-dissociated heterophoria tests in free space. Clin Exp Optom 2012;95(6):638-642. https://doi.org/10.1111/j. 1444-0938.2012.00785.x 